\title{
AN ATYPIC HERPES ENCEPHALITIS WITH WALLENBERG'S LATERAL MEDULLARY SYNDROME AND CD RECEPTORS DEFICIENCY
}

\author{
Ayşe Tuncal, Nüket Bavbek ${ }^{2}$ \\ Fatih University Medical School, Ankara: Department of Neurology ${ }^{1}$, Department of Internal Medicine²
}

\begin{abstract}
Summary: Herpes simplex encephalitis is a rare complication of Herpes virus infections. Innate immune mechanisms are the first line of defence encountered by invading infectious agents. A 41-year-old man was admitted to the neurology department with the complaints of fever, headache, vertigo, tinnitus and ataxia. His first brain Magnetic Resonance Imagine showed nodular lesions in the medulla oblongata and the second showed a new left occipital lobe lesion in addition. In sera, Herpes Simplex Virus IgG and M values were positive and liver enzymes were found to be elevated. His diagnosis was Herpes encephalitis with liver involvement. CD19, CD20, CD21, CD22, CD35 receptors were found to be diminished. In this case we want to address that one of the causes of Wallenberg's lateral medullary syndrome can be Herpes simplex virus-1 and probable immune system deficiency can be researched.
\end{abstract}

Key words: Herpes; Brain stem; $C D$ receptor

\section{Introduction}

Herpes simplex virus (HSV) belongs to a family of eight related viruses, including Herpes simplex virus type 1 (HSV-1) and 2 (HSV-2), Varicella-zoster virus (VZV), Epstein-Barr virus (EBV) and Cytomegalovirus (CMV) (10). In the course of a natural infection, HSV first infects the apical surfaces of the epithelium, than infects the peripheral endings of sensory neurons, transports through axons to the neuronal nuclei, and establishes a latent infection (12). The selective destruction of temporal and frontal lobe structures by herpes simplex encephalitis has been explained as a consequence of entry of the virus in the encephalon, through olfactory pathways or meningeal branches of the trigeminal nerves (5). However, it has been speculated that the virus might also be present in latent fashion in normal human brain, where it might be responsible for conditions such as herpes simplex encephalitis (2). Innate immune mechanisms are the first line of defence encountered by invading infectious agents (4).

Here we want to present a herpes encephalitis case with brain stem and liver involvement and CD receptors deficiency. In English language literature we couldn't find any alive HSV-1 Encephalitis patient with brainstem involvement and $\mathrm{CD}$ receptors deficiency.

\section{Case Report}

A 41-year-old man was admitted to the neurology department with the complaint of fever, headache, vertigo, tinnitus and ataxia. He had suffered herpes labialis about 4 months ago, which was diagnosed with Tzanck smear, and being treated with Acyclovir (1200 mg/day, one week).

His physical examination was normal but mild fever $\left(38{ }^{\circ} \mathrm{C}\right)$. His first neurological examination revealed right lid ptosis, decreased pain and temperature sensation either of the right face or of the left part of the body; vertigo which was increasing with head movement, cerebellar dysmetria of right arm-leg and cerebellar ataxia to the right side. His first Magnetic Resonance Imagine (MRI) showed nodular lesions in the posterolateral area of right medulla oblongata without contrast enhancement (Fig.1). The first diagnosis was Wallenberg's lateral medullary syndrome.

In basic laboratory findings; in sera: AST: $145 \mathrm{IU} / \mathrm{L}$ (N: 0-50), ALT: 132 IU/L (N: 0-50), GGT: 282 IU/L (N: 10-60) and ALP was 408 IU/L (N: 98-279). HSV-1 IgM: 1.4 positive index (Cut off 1.0 Method: EIA) (Negative <1.0). HSV-1 Ig G: 1.5 positive index (Cut off 1.0 Method: EIA) (Negative <1.0); Ebstein Barr Virus (EBV) IgG (VCA): 1.9 positive index (Negative <1.0) and Cytomegalovirus (CMV) IgG was 38 positive index (>6.0 Positive). White blood cell count was mildly high: $15700 / \mathrm{mm}^{3}(\mathrm{~N}$ : 4.5-11.0) with PNL $74.5 \%$.

HSV-2 IgM (EIA): 0.9 negative index (Negative <1.0); HSV-2 IgG: 0.04 Negative index (Negative <1.0) and Anti$\mathrm{HIVI} / \mathrm{II} \mathrm{gO}$ was negative $0.31 \mathrm{~S} / \mathrm{CO}$.

HSV-1 encephalitis and liver involvement was suspected and spinal tap was performed in the $24-48^{\text {th }}$ hours of the disease. The pressure of cerebrospinal fluid (CSF) and biochemical findings were normal except for pleocytosis ( 100 


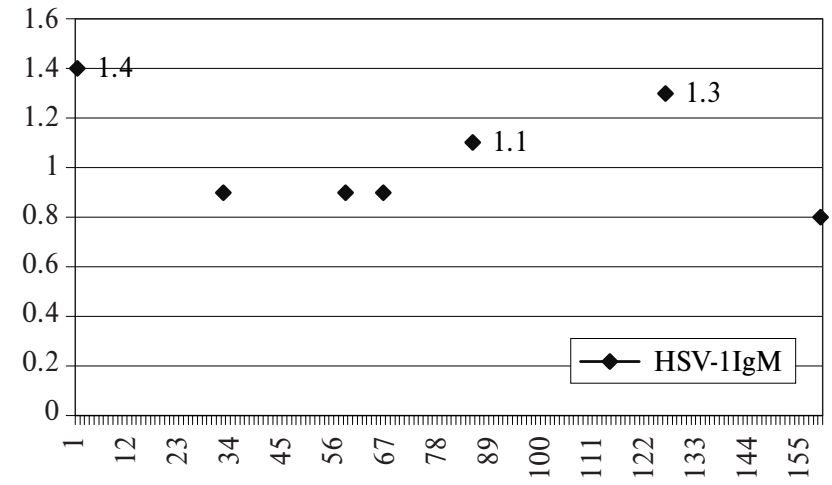

Graph 1a: Alteration of HSV-1 IgM with herpes labialis attacks. The numbers on the graph showed IgM levels at the time of attacks.

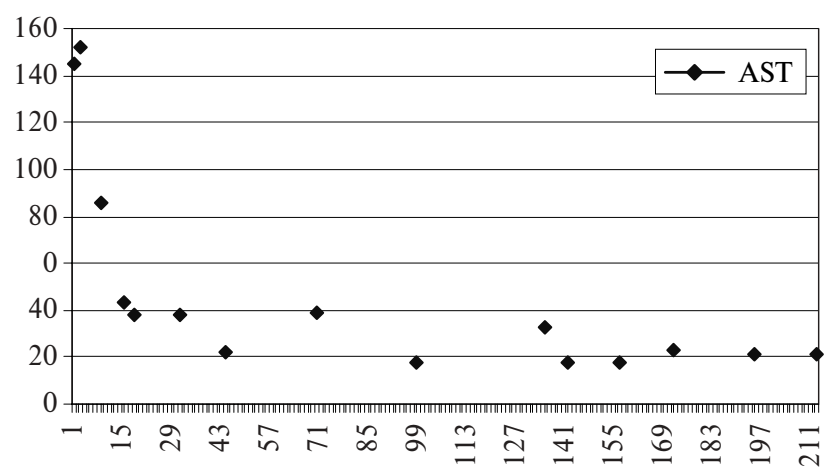

Graph 2a: Alteration of AST values.

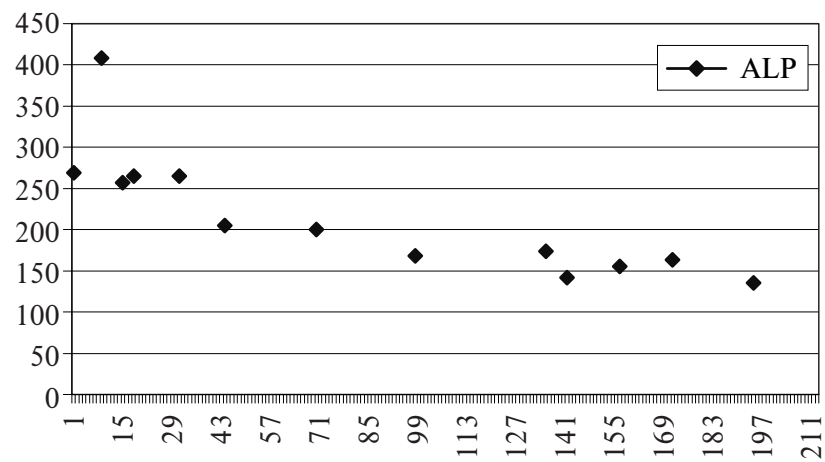

Graph 2c: Alteration of ALP values.

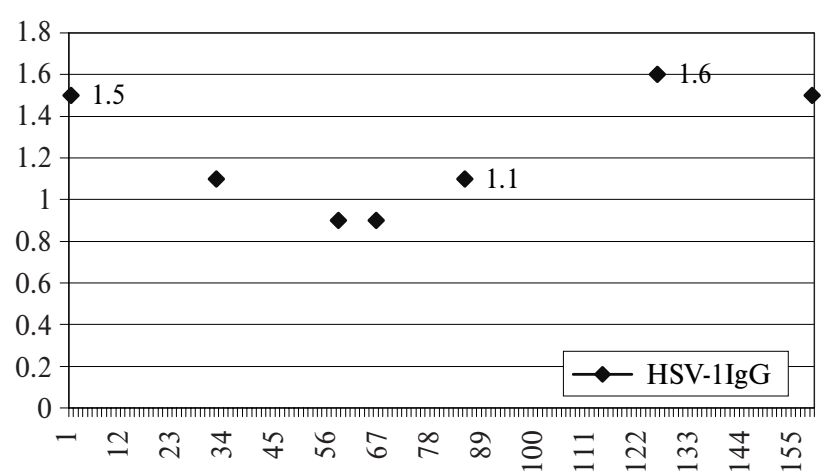

Graph 1b: Alteration of HSV-1 IgG with herpes labialis attacks. The numbers on the graph showed IgM levels at the time of attacks.

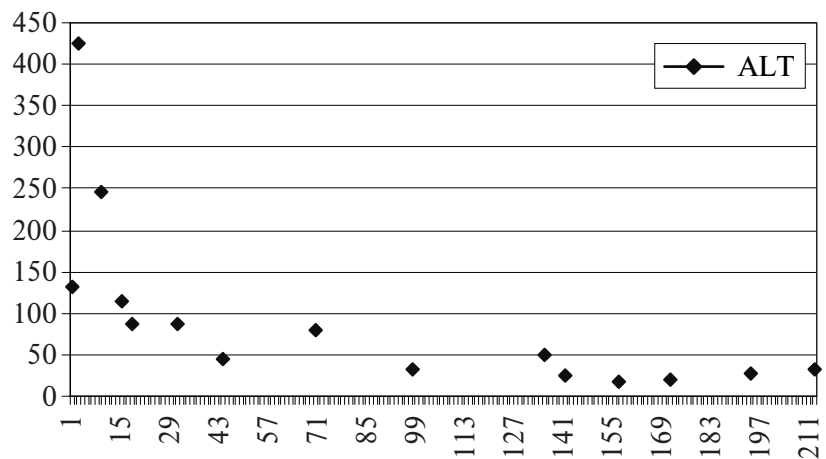

Graph 2b: Alteration of ALT values.

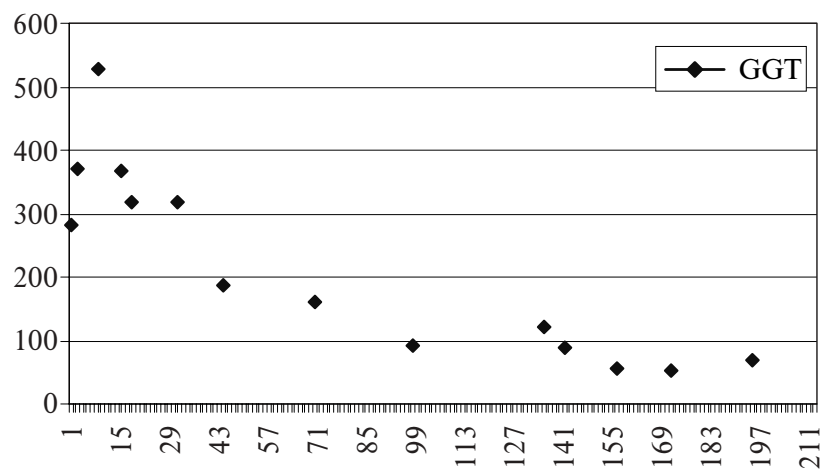

Graph 2d: Alteration of GGT values. 


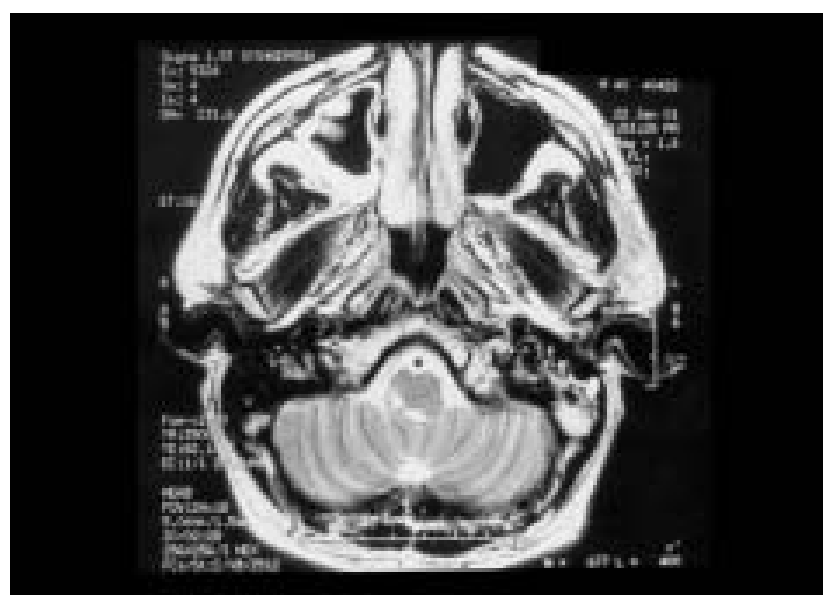

Fig. 1: Noduler lesions in right medulla oblangata.

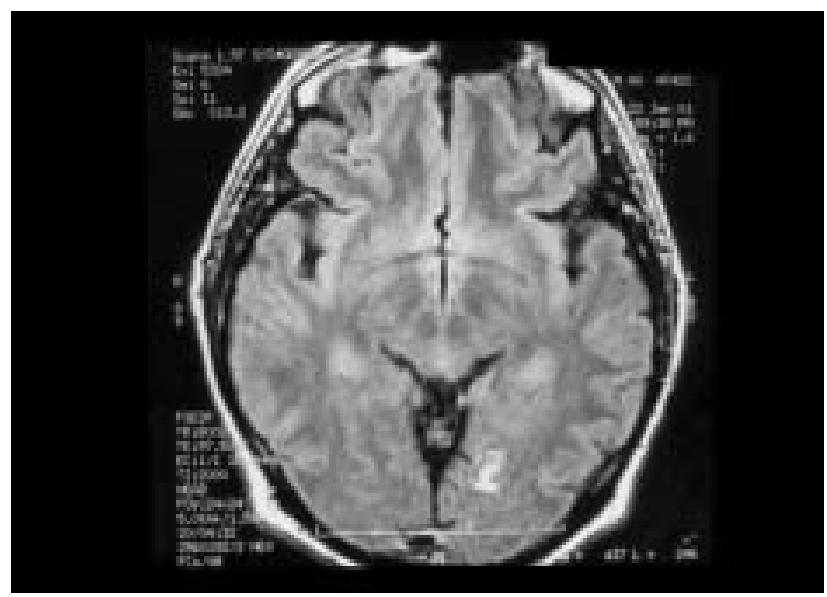

Fig. 2: A new lesion in left occipital lobe.

Tab. 1: CD receptor values of patient

\begin{tabular}{|l|c|c|}
\hline CD receptors & $\begin{array}{c}\text { Values } \\
(\%)\end{array}$ & $\begin{array}{c}\text { Normal } \\
\text { Values (\%) }\end{array}$ \\
\hline CD19 (Total B Lymphocytes) & 4 & $6.4-22.6$ \\
\hline $\begin{array}{l}\text { CD21 (Precursor B cells and } \\
\text { mature B cells; C3d R CR2 and } \\
\text { EBV receptor) }\end{array}$ & 6.08 & $7-23$ \\
\hline $\begin{array}{l}\text { CD20 (Precursor B cell subset; } \\
\text { B cells; follicular dendritic cells): }\end{array}$ & 3.55 & $7-23$ \\
\hline $\begin{array}{l}\text { CD22 (Precursor B cells and } \\
\text { mature B cells): }\end{array}$ & 3.39 & $7-23$ \\
\hline $\begin{array}{l}\text { CD35 (Granulocytes; monocytes; } \\
\text { dendritic cells; B cells; } \\
\text { erythrocytes (C3b"CR1"): }\end{array}$ & 6.83 & $7-23$ \\
\hline CD3 (Total T Lymphocytes): & 73.77 & $60-85$ \\
\hline CD4 (Helper/Inducer T Lymphocytes): & 43.67 & $29-59$ \\
\hline CD16+56 (NK cells): & 25 & $5.6-30.9$ \\
\hline CD4/CD8 (Helper/suppressor): & 1.5 & $0.6-2.8$ \\
\hline $\begin{array}{l}\text { CD8 (Cytotoxic/supressor } \\
\text { Lymphocytes): }\end{array}$ & 28.97 & $19-48$ \\
\hline
\end{tabular}

cells per cubic millimetre, $80 \%$ lymphocytes). In CSF; HSV-1 IgM and polymerase chain reaction for HSV-1 was negative.

Abdominal ultrasonography (USG) was normal and MRAngiography of intracranial and extra cranial arteries were normal.

Acyclovir (IV) $10 \mathrm{mg} / \mathrm{kg}$ in the interval of 8 hours was started and continued for 10 days. At the third day of treatment, he had upper repiratory tract infection and complaint of difficulty in accommodation. The ophthalmologic examination was normal. Brain MRI revealed a new lesion in left occipital lobe (Fig. 2). Fifteenth day of illness, the patient was discharged from the hospital with lids pitosis and mild weakness. Total improvement of the symptoms was seen in 4 weeks. After 4 months, diffusion MRI was performed (not shown); encephalomalatic area secondary to encephalitis was seen either the posterolateral area of right medulla oblongata or at the cortical, subcortical area near calcarine sulcus of left occipital lobe.

In the last 12 months, HSV-1 Ig G and M values was measured while having recurrence of herpes labialis (Graph $1 \mathrm{a}$ and $\mathrm{b}$ ) which was diagnosed with Tzanck smear for 3 times. We also followed up the progress of his liver enzymes (Graph 2).

Because of being probable immune system deficiency, lymphocyte subpopulations was researched (Table 1).

\section{Discussion}

HSV is a common cause of infections of the skin, mucous membranes and less frequently oesophagus and brain (10). In general; the lesions take the form of an intense hemorrhagic necrosis of the inferior and medial parts of the temporal lobes and orbital parts of the frontal lobes. Although, it is known that HSV-1 DNA could be detected at all levels of the brain from the ganglia to the cortex but significantly lower virus yields were obtained in cultures of brain- stem derived astrocytes compared with cortex-derived astrocytes (3).

The most known syndrome of brain stem involvement with the triad of Horner's syndrome (ptosis, myosis, anhydrosis), ipsilateral ataxia and contralateral hypalgesia are Wallenberg's lateral medullary syndrome that was originally described as secondary to occlusion of the posterior inferior cerebellar artery (PICA) and vertebral artery (11). In our patient there was ptosis without miosis or anhidrosis. In the medulla, the descending pathway is located in the posterolateral retro-olivary area, and in the cervical cord the fibbers run in the posterior angle of the anterior horn. According to the authors, some of the fibbers supplying sudomotor neurons run outside this area but remain ipsilateral (1). In our opinion; sudomotor neurons were selected from the lesion of medulla oblongata in this patient resulting in only ptosis.

Liver involvement can be mild but can result in fulminant hepatic necrosis and death. The diagnosis often is 
missed because disease can present without typical skin lesions, oral ulcerations, hepatomegaly or suggestive laboratory findings. Pregnancy and immunodeficiency have been identified as risk factors for liver involvement in systemic herpes virus disease. (3). The liver enzymes were high at the basic laboratory results of our patients, which completely resolved in 5 months without any complication (Graph 1).

Complement is important not only in the effectors function of innate immunity but also in the stimulation of memory B cell responses to viral-infected cell antigens in both blood and peripheral tissues (4). The complement system represents a cascade of serum proteins, which provide a major effectors function in innate immunity via complement receptors $\mathrm{CD} 21 / \mathrm{CD} 35$ and the membrane protein complex CD19/CD21 that they enhance the B cell memory response (4,6). CD22 regulates lymphocyte adhesion and activation. It is a transmembrane glycoprotein lecithin found exclusively on B-lymphocytes and is known to play a regulator role in the immonologic activation of these cells (9). Because of the deficiency of these receptors; absence of mature B cells and follicles with marginal zone macrophages and absence of germinal centres with follicular dendritic cells correlated with lack or substantial reduction of protective IgM and IgG responses respectively (7). In our patient there was CD19, CD20, CD21, CD22, CD35 receptors deficiency (Table 1) and inappropriate $\operatorname{IgM}$ and IgG responses (Graph 2).

A test called ELISA (enzyme-linked immunosorbent assay) is $85 \%$ accurate in detecting the herpes virus and $100 \%$ accurate in determining the relevant strain (10). IgG bands can be detected in CSF specimens of the patients, as early as day 6 up to day 1088 (13).

Polymerase chain reaction (PCR) studies are used to diagnose disease in culture-negative patients. The PCR technique is highly accurate, with a sensitivity of $95 \%$ and specifity of $94 \%$. A full $98 \%$ of patients with herpes encephalitis have positive results on PCR testing within 3 to 18 days after disease onset (10). In our patient the results of CSF ELISA and PCR was negative. Failure of PCR in our patient is most likely due to the time $\left(24-48^{\text {th }}\right.$ hours of the disease) of obtaining CSF. Positive serological findings of HSV are not relevant at all for actual diagnosis of herpetic enfection according to ability for persistance of herpes viruses in organism.
In conclusion, we want to stress that in the aetiology of Wallenberg's syndrome HSV-1 encephalitis might be excluded and lymphocyte subpopulations should be studied for probable immunodeficiency.

Author's remark: With "Tzanck smear", we want to say that for detecting a herpes infection we used "Tzanck test" as the most commonly used diagnostic tool for detecting a herpes infection.

\section{References}

1. Adams, RD, Victor M, Ropper AH. Principles of neurology. 6th ed. USA: McGraw-Hill, 1997:529.

2. Baringer, JR., Pisani, P. Herpes simplex virus genomes in human nervous system tissue analyzed by polymerase chain reaction. Ann Neurol 1994:36:823-9.

3. Bergstrom T, Conradi N, Hansson E, Liljeroth A, Vahlne A. Resistance of rat CNS to brainstem infection with herpes simplex type 1. Acta Neuropathol (Berl) 1994;87:398-404.

4. Da Costa XJ, Brockman MA, Alicot E et al. Humoral response to herpes simplex virus is complement-dependent. Immunology 1999;96:12708-12.

5. Damasio AR, Van Hoesen GW. The limbic system and the localisation of herpes simplex encephalitis. J Neurol Neurosurg Psychiatry 1985;48:297-301.

6. Fearon DT, Carroll MC. Regulation of B lymphocyte responses to foreign and self-antigens by the CD19/21 complex. Annu Rev Immunol 2000;18:393-422.

7. Fehr T, Lopez-Macias C, Odermatt B et al. Correlation of anti-viral B cell responses and splenic morphology with expression of B cell-specific molecules. Int Immunol 2000:12:1275-84.

8. Fingeroth JD. Infections of the liver. Herpesvirus Infection of the Liver. Infectious Disease Clinics of North America 14(3) Sep. 2000 http://home.mdconsult.com

9. Hennet T, Chui D, Paulson JC, Marth JD. Immune regulation by the ST6Gal sialyltransferase. PNAS Online 1998;95:4504-9.

10. Nadelman MC, Newcomer DV. Herpes simplex virus infections. New treatment approaches make early diagnosis even more important. Postgrad Med 2000; 107:189-200.

11. Sacco RL, Freddo L, Bello JA, Odel JG, Onesti ST, Mohr JP. Wallenberg's lateral Medullary Syndrome. Clinical-Magnetic Resonance Imaging Correlations. Arch Neurol 1993;50:609-14.

12. Tran LC, Kissner JM, Westerman LE, Sears AE. A herpes simplex virus 1 recombinant lacking the glycoprotein $\mathrm{G}$ coding sequences is defective in entry through apical surfaces of polaized epithelial cells in culture and in vivo. Microbiology. Proc Natl Acad Sci USA 2000;97:1818-22.

13. Vaheri A, Keski-Oja J, Salonen EM, Koskiniemi ML. Cerebrospinal fluid IgG bands and virus-specific IgG,IgM and IgA antibodies in herpes simplex virus encephalitis. J.Neuroimmunol 1982;3:247-61.

Submitted July 2003.

Accepted November 2003.

Dr. Ayşe Tunca,

Fatih Üniversitesi Tip Fakültesi, Çiftlik Caddesi No:57, 06510 Emek-Ankara, Türkiye. e-mail:etunca@e-kolay.net 